\title{
Using Qualitative Methods to Explore Communication Practices in the Context of Patient Care Rounds on General Care Units
}

\author{
Milisa Manojlovich, PhD, RN, FAAN ${ }^{7}$ (D), Molly Harrod, PhD², Timothy P. Hofer, $M D^{2,3}$, \\ Megan Lafferty, $\mathrm{PhD}^{7}$, Michaella McBratnie, $B S^{7}$, and Sarah L. Krein, $P h D^{2,3}$
}

${ }^{1}$ School of Nursing, University of Michigan, Ann Arbor, MI, USA; ${ }^{2}$ Center for Clinical Management Research, Department of Veterans Affairs Ann Arbor Healthcare System, Ann Arbor, MI, USA; ${ }^{3}$ Department of Internal Medicine, University of Michigan Medical School, Ann Arbor, MI, USA.

BACKGROUND: Poor communication between physicians and nurses is a significant contributor to adverse events for hospitalized patients. Overcoming communication difficulties requires examining communication practices to better understand some of the factors that affect the nurse-physician communication process.

OBJECTIVE: To develop a more detailed understanding of communication practices between nurses and physicians on general care units. We focused on patient care rounds as an important activity in the care delivery process for communication.

DESIGN: Qualitative study design

PARTICIPANTS: A total of 163 physicians, registered nurses, and nurse practitioners who worked on prespecified general care units in each of four hospitals in the Midwest.

APPROACH: On each unit, data collection consisted of 2 weeks of observing and shadowing clinicians during rounds and at other times, as well as asking clinicians questions about rounds and communication during interviews and focus groups. A directed content analysis approach was used to code and analyze the data.

KEY RESULTS: Workflow differences contributed to organizational complexity, affecting rounds and subsequently communication practices, both across and within provider types. Nurse and patient participation during rounds appeared to reduce interruptions and hence cognitive load for physicians and nurses. Physicians adopted certain behaviors within the social context to improve communication, such as socializing and building relationships with the nurses, which contributed to nurse participation in rounds. When rapport was lacking, some nurses felt uncomfortable joining physicians during rounds unless they were explicitly invited.

CONCLUSIONS: Improving communication requires bringing attention to three contextual dimensions of communication: organizational complexity, cognitive load, and the social context. Initiatives that seek to improve communication may be more successful if they acknowledge the complexity of communication and the context in which it occurs.

Electronic supplementary material The online version of this article (https://doi.org/10.1007/s11606-019-05580-9) contains supplementary material, which is available to authorized users.

Received May 7, 2019

Accepted November 25, 2019

Published online December 12, 2019
KEY WORDS: physician-nurse relations; collaboration; teaching rounds; hospital medicine.

J Gen Intern Med 35(3):839-45

DOI: $10.1007 / \mathrm{s} 11606-019-05580-9$

(c) Society of General Internal Medicine 2019

\section{BACKGROUND}

Poor communication between physicians and nurses has been identified as a contributor to adverse events for hospitalized patients, ${ }^{1-3}$ ranging from increased length of stay ${ }^{4}$ to death. ${ }^{5} \mathrm{~A}$ few studies have examined barriers to effective nurse-physician communication, including the frequency with which communication occurs, ${ }^{6,7}$ while others have explored how factors such as information technology play a mediating role in the communication process. ${ }^{8,9}$ Yet despite years of study, communication difficulties persist across healthcare settings and specialties. ${ }^{10,11}$ Thus, overcoming communication difficulties requires examining communication practices to better understand some of the factors that affect the nurse-physician communication process.

Several factors may contribute to poor communication. First, the hierarchical nature of the relationship between nurses and physicians may impede communication and contribute to suboptimal care. ${ }^{12}$ Second, contextual factors, such as differences in workflow patterns, might inhibit opportunities for communication. ${ }^{13}$ Finally, the cognitive load experienced by physicians and nurses as they work has been identified as a factor affecting certain activities, such as handoffs between physicians ${ }^{14}$ and nursing procedures, ${ }^{15}$ but the relationship between cognitive load and nurse-physician communication has not been directly examined.

The purpose of this study was to develop a more detailed understanding of communication practices between nurses and physicians on general care units, including factors that affect and are affected by nurse-physician communication. General care units include non-specialty units such as medical, surgical, and "mixed" care units. Specifically, we focused on patient care rounds (i.e., a sequential review of a group of patients ${ }^{16}$ ), as an important activity in the care delivery process for interpersonal and inter-professional communication. Physicians and nurses typically deliver care in parallel, asynchronous workflow 
patterns, ${ }^{17}$ so patient care rounds represent the one daily activity where both groups can converge to share information and address patient problems. Exploring factors that influence communication during patient care rounds may provide insights into the communication practices of nurses and physicians more generally, helping us reach our ultimate goal of identifying key opportunities for improving communication between healthcare providers.

\section{METHODS}

\section{Study Design and Site Selection}

We conducted this qualitative study using interview, focus group, shadowing, and observation data collected as part of a larger project designed to understand how communication technologies facilitate or hinder communication between nurses and physicians on general care units. ${ }^{8} \mathrm{~A}$ focused analysis using these data was conducted to explore patient care rounds as a focal point for understanding communication practices between physicians and nurses.

Four hospitals located in three states in the Midwest United States participated in this study. These sites were purposefully selected from an initial sample of 74 hospitals that responded to a survey about communication technologies and nontechnological communication practices. ${ }^{18}$ We used survey results to place hospitals into one of four categories, based on the degree of adoption of technology (high/low) and nontechnology-based communication practices (high/low). We then chose 2 hospitals from each category (e.g., high adoption of technology, high non-technical communication practices; high adoption of technology, low non-technical communication practices) and conducted phone interviews with nurses and physicians at eight of the surveyed hospitals to learn more about their communication practices. Finally, we selected four of the eight hospitals for more in-depth investigation involving qualitative data collection. Selection criteria included having sites that used different electronic health record systems, a combination of academic medical centers as well as community hospitals of different sizes, and one site from the United States Department of Veterans Affairs (VA) health system. As we had established relationships with these hospitals during the telephone interview phase, all four hospitals that we initially contacted agreed to participate (see Table 1). The university's institutional review board (IRB) approved the study and deemed the sites "not engaged" because none was involved in data collection. However, we obtained site-specific IRB approval if required by the site.

\section{Participant Recruitment and Data Collection}

We recruited a convenience sample of physicians, registered nurses, and nurse practitioners (NPs) who worked on a general care unit chosen by leadership at each hospital to participate in the study, using a face-to-face approach. No clinicians refused to be observed or dropped out. ML, a $\mathrm{PhD}$-prepared anthropologist, and two trained research assistants collected data during 2 weeks of observing and shadowing clinicians during rounds and at other times on each unit. They also conducted interviews and focus groups in private conference rooms asking questions about communication and rounds using a previously pilot-tested guide ${ }^{19}$ (Appendix). Participants were informed about the study purpose as part of the informed consent process. No interviews were repeated. We did not collect demographic data other than role. Data were collected sequentially from February to September 2017, with a 6- to 8-week gap between site visits, to allow us to adjust data collection procedures and conduct preliminary analysis, using lessons learned from one site to inform subsequent data collection. Data saturation at each site was achieved through extended time in the field, use of various data collection methods, and participation of different healthcare providers. Handwritten field notes created during observation and shadowing were transcribed by observers to create electronic field notes, while audiorecorded focus groups and interviews were transcribed verbatim by a proprietary transcription service.

\section{Data Analysis}

We used a directed content analysis approach ${ }^{20}$ to code and analyze the entire data set, including field notes generated during observation and shadowing. Three authors (MM, ML, $\mathrm{MMcB}$ ) independently coded $20 \%$ of the same transcripts then met to compare codes. During regular coding meetings (including MH and SK), we arrived at consensus on code categories by discussing the reasons for any discrepancies until differences were resolved, then documented the code definitions in a codebook. We used an iterative process to compare results of application of codes to the transcripts. If new codes emerged during the coding process, they were added to the codebook then prior coded transcripts were reviewed to determine if new codes were applicable. Once agreement was consistent, remaining transcripts were divided among team members (ML, MM, MMcB) and coded independently. Code reports, where text coded the same is aggregated, provided the opportunity to check for consistency in the application of codes. Themes arose from the data using an inductive approach. All authors were involved in data analysis, which provided the opportunity for reflexivity among team members who came from various disciplines: medicine $(\mathrm{TH})$, nursing (MM and SK), and anthropology (ML, MH, MMcB). We discussed our perceptions, insights, and potential biases to ensure they were accounted for in the interpretation of data, and to ensure a high level of trustworthiness, or credibility of analysis. ${ }^{21}$ We documented the reasons for analytic decisions (e.g., through memoing, meeting notes) and used NVivo $8^{\circledR}$ to manage and arrange the data in ways that helped us to see relationships. Two sites invited us to present findings where participants validated results through member checking. ${ }^{22}$ 
Table 1 Participating Hospital Characteristics

\begin{tabular}{|c|c|c|c|c|}
\hline $\begin{array}{l}\text { Hospital } \\
\text { ID }\end{array}$ & $\begin{array}{l}\text { Bed } \\
\text { Size }\end{array}$ & Location and teaching status & Unit type/characteristics & MD staffing model \\
\hline Site 1 & 200 & Urban community hospital & $\begin{array}{l}\text { A 37-bed general care unit laid out in L shape and } 1 \\
\text { separate hall }\end{array}$ & $\begin{array}{l}\text { Hospitalists co-located with } \\
\text { nurses on a unit }\end{array}$ \\
\hline Site 2 & 600 & Urban academic medical center & $\begin{array}{l}\text { A 10-bed transplant unit laid out in a single short, } \\
\text { narrow hall } \\
\text { A 32-bed telemetry unit laid out in U shape }\end{array}$ & Teaching teams \\
\hline Site 3 & 100 & $\begin{array}{l}\text { Urban VA Hospital affiliated with } \\
\text { academic medical center }\end{array}$ & A 14-bed general care unit laid out in $\mathrm{T}$ shape & Teaching and hospitalist teams \\
\hline Site 4 & 600 & Urban community hospital & $\begin{array}{l}\text { A 16-bed general care unit specializing in oncology } \\
\text { care, laid out in U shape }\end{array}$ & $\begin{array}{l}\text { Hospitalists covering multiple } \\
\text { units }\end{array}$ \\
\hline
\end{tabular}

\section{RESULTS}

A total of 163 clinicians within the four hospitals participated in the study as detailed in Table 2. Approximately $8-12 \mathrm{~h}$ was spent in general observation at each site. A shadowing session lasted about $2 \mathrm{~h}$; nurse focus groups conducted before or after scheduled shifts were between 45 and 60 min long. We conducted interviews, typically $20 \mathrm{~min}$ long, with physicians during their work day. We organized themes arising from analysis into three contextual dimensions of communication: organizational complexity, cognitive load, and social context. These are displayed in Table 3 with representative quotes and described in detail below.

\section{Organizational Complexity}

Workflow differences are an inherent part of healthcare systems and were a prominent theme affecting rounds and subsequently communication practices, across and within provider types. Nursing workflow caused a significant barrier to participation during rounds and thus communication because nurses were frequently busy with tasks in one patient's room while physicians were conducting rounds in another. Workflow differences led one physician at site 3 to comment during a small group interview that, "sometimes it is a challenge to find somebody." Another physician during the same interview commented that it would be helpful if nurses joined rounds, and noted that an important barrier to nurse participation in rounds was workflow differences, saying, "My workload in the morning is to see every patient in some certain order. But

Table 2 Study Participants

\begin{tabular}{llllll}
\hline \hline & $\begin{array}{l}\text { Site } \\
\mathbf{1}\end{array}$ & $\begin{array}{l}\text { Site } \\
\mathbf{2}\end{array}$ & $\begin{array}{l}\text { Site } \\
\mathbf{3}\end{array}$ & $\begin{array}{l}\text { Site } \\
\mathbf{4}\end{array}$ & Total \\
\hline RN interview/FG partici- & 24 & 33 & 18 & 11 & 86 \\
pants & 7 & 6 & 4 & 7 & 24 \\
RN shadowing & 2 & 2 & 1 & 0 & 5 \\
NP interview participants & 0 & 3 & 0 & 0 & 3 \\
NP shadowing & 3 & 10 & 14 & 5 & 32 \\
MD interview & 3 & 6 & 4 & 0 & 13 \\
participants & 39 & 60 & 41 & 23 & 163 \\
MD shadowing & Total participants & & & & \\
\hline
\end{tabular}

$R N$, registered nurse; $F G$, focus group; $N P$, nurse practitioner their workload is, 'I gotta administer patients'....medications to all these 4, and then I have to do other things."'

Workflow differences among various physician teams on general care units resulted in inconsistent and overlapping rounding times, possibly reducing opportunities to communicate. A nurse from site 2 during a focus group commented, "Like the surgery teams will...round at 8:00 this day and now somebody is in the clinic all day, so they won't round until 11:30 the next day," highlighting the inconsistency of rounding patterns within the same specialty. A physician from site 3 confirmed this during a small group interview saying, "We don't round at the same time every day, so that makes it difficult for the nurses to be able to [participate in rounds],"with implications for communication. Nurses told us that patients often expressed frustration regarding inconsistent rounding times because patients and families wanted to communicate with physicians. During a focus group, a nurse at site 2 said, "I know it's more frustrating to the patients than anybody else," while another nurse from the same focus group provided an explanation for the patient's frustration saying, "They [patients] always want to know, 'when's my doctor coming? What time is he coming, because my family wants to be here.""

During observation, a nurse from site 2 told us that it was not feasible for nurses to participate in rounds and communicate then because of the overlap in rounding times, a consequence of the way physicians' patients were distributed among nurses. Each nurse could be assigned patients from more than one physician group, and when multiple physician teams were on the floor at the same time, nurses could not be present at rounds for two patients from two different teams, affecting their ability to communicate with physicians during rounds. As a nurse from site 3 said during a focus group, "I try to catch them [doctors] during rounds if there's something specific I need about a patient. But that's not always possible because you might have four different patients from four different teams." In contrast to the other sites, site 1 was staffed by hospitalists who were co-located with nurses on the unit and this hospitalist staffing model, using geographical co-location, helped reduce workflow differences so that nurses were available to communicate with physicians during rounds. 
Table 3 Contextual Dimensions of Communication with Representative Quotes

\begin{tabular}{|c|c|c|}
\hline Dimensions & Theme & Representative Quotes \\
\hline $\begin{array}{l}\text { Organizational } \\
\text { complexity }\end{array}$ & $\begin{array}{l}\text { Differences in workflows within and across } \\
\text { provider types. }\end{array}$ & $\begin{array}{l}\text { "Sometimes they are [nurses] busy and so our rounding...you know, maybe } \\
\text { it's during the hour where they have to administer the morning medications. } \\
\text { There's conflicts during that timing." } \\
\text { - Physician, site } 3 \\
\text { "I usually write down the physician's name and their number, and depending } \\
\text { upon who it is, I have some idea of when they might be here or not. So say if } \\
\text { it's going to be the oncologists, Dr. X I know comes in early... If it's one of } \\
\text { the hospitalists, they could be rounding any time..." } \\
\text {-Nurse, site } 4\end{array}$ \\
\hline Cognitive load & $\begin{array}{l}\text { Nurse participation in rounds decreases nurse- } \\
\text { to-physician pages later in the day. } \\
\text { Nurses remind doctors of additional } \\
\text { information and forgotten orders. } \\
\text { Patients play a role in reducing or contributing } \\
\text { to cognitive load. }\end{array}$ & $\begin{array}{l}\text { "Now, Dr. X...does call us [for rounds]. Because he [does not] want to be } \\
\text { paged." - Nurse, site } 2 \\
\text { "...I'll see } 4,5 \text { patients one time... Sometimes I might forget to order those } \\
\text { things... So they [nurses] call me, 'you said this thing,' but I did not order so } \\
\text { far, so that helps me a lot." - Physician, site } 4 \\
\text { "Or sometimes, if I have not seen them [physicians], I'll ask the patient } \\
\text { "has... your doctor rounded today?' 'Oh yeah, they were in." - Nurse, Site } 4 \\
\text { "I learn a lot of stuff from my patients." - Nurse, site } 3 \text {. }\end{array}$ \\
\hline Social context & $\begin{array}{l}\text { Physicians' higher social status allows them to } \\
\text { include or exclude nurses during rounds. }\end{array}$ & $\begin{array}{l}\text { "We try as best we can to get the nurse. .. to be present when the patient is } \\
\text { being either seen or we are discussing during rounds." - Physician, Site } 3 \\
\text { "Yeah, sometimes you go in with the team when they are rounding, and } \\
\text { they'll look at you like why are you standing there. Are we in your way, and } \\
\text { you are like no, I just want to be on the same page." - Nurse, site } 2 \\
\text { "But there's a few that try to walk around and avoid you at all costs, because } \\
\text { they are like, "well I have not even seen the patient yet, so I do not even } \\
\text { wanna listen to you."" - Nurse, site } 1\end{array}$ \\
\hline
\end{tabular}

\section{Cognitive Load}

Cognitive load is the amount of information processing activity imposed on working memory at any one time, and is affected by both internal (e.g., common knowledge or lack thereof) and external (e.g., environment) factors. ${ }^{23}$ In this study, cognitive load was largely derived from external factors such as interruptions reported by both physicians and nurses. Nurse and patient participation during rounds was reported to reduce interruptions and hence cognitive load for physicians and nurses largely because of the communication that took place during rounds.

First, physicians commented that by including nurses on rounds, they received fewer calls or pages throughout the day, and reported fewer interruptions. One physician from site 3 said during a small group interview, "So, the pages would stop because they would know like, 'Oh, they're... they're coming down, you know, the hallway so they'll be here in a few minutes. We'll ask them when they get here." However, when this opportunity to exchange information was missed, nurses had to interrupt physicians afterwards when the physicians were focused on other tasks, adding to physicians' cognitive load. Participating in rounds reduced the cognitive load for nurses as well. During a site 2 focus group, one nurse commented, "That would solve so many of the problems because we wouldn't sit there and have to go, 'I wonder if they need me to call them on this or whatever."'

Second, nurses acted as a reminder system, helping reduce physicians' cognitive load by reminding physicians to address certain issues that they may have forgotten otherwise. During an interview, a physician from site 4 noted, "So, if you're rounding with the nurse, that's the...there's a major part of the
communication...Definitely even if I'm missing some orders or if there is a wrong order, they can always call you back. If there's no communication, they... they won't know what it is." Nurses also reported having to think less about patient care issues if they were included in rounds. One site 2 nurse during a focus group said, "if I miss them during rounds, if I'm doing something, it's more common for me to kind of have to either figure out what's happening, or I have to page them and be like, 'what's the plan?"'

Third, patient involvement in rounds played a role in reducing clinicians' cognitive load. Sometimes nurses would hear information from patients that would then need to be confirmed by the physician, possibly interrupting the physician in some other task. A more extreme scenario that physicians as well as nurses talked about wanting to avoid was when patients tried to get some concession by playing one provider against the other. In this instance, both felt that the best strategy was for nurses to participate in rounds to ensure that patients received a consistent, unified message. During an interview, a physician from site 4 said, "Some of the nurses come [so] whatever that's told to the patient is the same, we are on the [same] page because at times some of the patients try to play a trick, 'Oh, the doctor said something else.'...So to avoid that...if they're free, they come in. That really helps."

\section{Social Context}

Physicians talked about behaviors within the social context that they adopted to improve communication. Some physicians socialized and built relationships with nurses that facilitated communication both in and out of the context of rounds. One physician from site 4 said during an interview that he tried 
"to spend more time on the floors. I try to socialize with them a lot on my rounds at work... I'm always involv[ing] nurses." Many physicians actively sought out nurses as confirmed by a nurse at site 4 who said during an interview, "some physicians seek you out when they round on their patients." Physicians who sought out nurses to communicate with them during rounds contributed to a more positive social context because nurses felt as though they were part of the care team. For instance, one site 2 nurse said during a focus group, "That's why I like rounding. I feel like they do make you feel like you're part of the team." Physicians also communicated with nurses many times throughout the day, not just during rounds. One site 1 physician said during a small group interview, “...I think you need to have conversation with the person who's taking care of your patient or following out your orders." At site 1, we observed hospitalists and nurses calling each other by their first names and having frequent informal conversations in the halls, and this social context facilitated communication. One site 1 nurse said during a focus group, "I think during the day, it's nice that they're doing the rounds, so we can actually physically talk to them...".

However, when rapport was lacking, some nurses felt uncomfortable joining physicians during rounds unless they were explicitly invited, as we heard while interviewing a nurse from site 2 who said, "I feel like all the nurses would feel more comfortable with the physicians if they just took the time to stop and say 'hey, we're doing our rounds'..." Another site 2 nurse said while being shadowed that the physicians rarely stayed or were rarely seen on the unit after rounds and that she felt some reservations about talking directly to the physicians about the patients, suggesting an association between the lack of rapport and communication. We heard from nurses that while some physician groups valued building relationships with them, others appeared not to. During an interview, a site 4 nurse told us about a physician group that built rapport through communication with the nursing staff during rounds, "When we had family practice docs that, you know, saw their patients and rounded regularly and you get to build up that rapport that they knew you, knew that your assessment skills were good and that you knew what you were doing and they would ask for suggestions sometimes. I don't see that as often now." One site 2 nurse took a proactive approach to attending rounds and communicating with physicians, saying during a focus group, "Well, typically I have to see them coming around or else I'm not part of the rounds...I basically just stand and listen to what they're saying and if there's something that I have that I know...they need...I will just jump in and mention it."

\section{DISCUSSION}

Results of our qualitative study revealed three factors: organizational complexity, cognitive load, and the social context that interacted dynamically to influence communication practices both during and outside of patient care rounds. After reviewing the literature describing theoretical frameworks for examining communication, we found that Pirnejad's communication space framework closely aligned with our themes even though it was initially developed to describe more specifically how information and communication technology (ICT) can enhance interpersonal communication in healthcare. ${ }^{23}$ We can use this framework to facilitate interpretation of our results after analysis. ${ }^{24}$. Pirnejad posited that the context of a communication exchange is important to communication improvement efforts because the context has a profound effect on communication through three crucial dimensions: organizational complexity, cognitive load, and the social context. ${ }^{23} \mathrm{We}$ used these contextual dimensions to frame our findings, examining patient care rounds rather than ICT as an important conduit for interpersonal communication.

Organizational complexity created barriers to nurse participation in rounds that hindered communication, with the consequence that the cognitive load for physicians and nurses was increased later in the day for both groups. Using behaviors relating to the social context, physicians tried to build relationships with nurses, as a way to facilitate communication and this in turn improved nurse participation in rounds. However, when physicians did not seek to build relationships with nurses, there were descriptions of resulting missed opportunities for communication during rounds and at other times. Our findings offer support for initiatives that seek to encourage inter-disciplinary rounding as a way to improve the quality of patient care because the rounding process was described by both doctors and nurses as the one formal daily activity where communication about patient care issues occurs that would benefit from input from nurses as well as physicians. ${ }^{25}$

Organizational complexity contributed to workflow differences that were a formidable barrier to inter-professional participation and thus communication during patient care rounds. Similar to findings by others, ${ }^{17,}{ }^{26}$ this study found disconnected physician and nurse workflows, which have been characterized as "parallel play," ${ }^{, 27}$ where individuals work alongside but do not interact with one another. Some studies have found that strategies such as localizing or regionalizing physicians to specific units may be a way to facilitate more interactions between physicians and nurses, ${ }^{6,28}$ and improve nurse presence at rounds while decreasing mean rounding time. ${ }^{28}$ However, broad-scale adoption of these approaches has not occurred, suggesting the presence of context-specific barriers that need to be identified and addressed before such strategies can be successful.

We found that nurse participation in rounds reduced the cognitive load for both physicians and nurses who reported that by discussing the patient's status together with the patient, the nurse, physician, and patient all understood the plan for the day during rounds. Thus, the need for pages to the physician or calls to the nurse seeking clarification later was reduced. Others have also found a reduction in pages physicians receive later in the day as a result of having nurses participate in 
rounds, ${ }^{29}$ which reduces cognitive load by reducing interruptions, ${ }^{30}$ a known contributor to adverse patient events such as medication errors. ${ }^{15}$ Others have reported increased patient satisfaction as a result of patients being included in rounds, ${ }^{29}$ but the effect of patient participation in rounds on cognitive load is a new finding that needs further study. It is plausible to suggest that when patients believe they have received conflicting information because physicians and nurses do not provide information together, that cognitive load for nurses and physicians can increase because effort has to be expended by both of them to resolve any discrepancies.

Related to the social context, we found that both nurses and physicians identified social interactions and building rapport as contributing to better relationships that improved communication. The combination of better relationships and communication created a context where nurses then participated in rounds. When physicians invited nursing input and attendance during rounds, nurses felt that their input was valued, with the result that nurses were more comfortable communicating with physicians during rounds and at other times. We also found however that some nurses did not feel welcomed by physicians during rounds, with the result that nurses either did not go to rounds or were mostly passive participants. One study conducted audits of the number of physician calls inviting nurses to rounds, and publicly displayed a graph of the frequency with which physicians called nurses for rounds, ${ }^{17}$ which was successful in changing physician behavior. The effect of interpersonal relationships on communication has been reported by others, ${ }^{31,32}$ and indeed, communication has been defined as the development of shared understanding by building and maintaining relationships. ${ }^{23}$ Our study provides further evidence of the importance of relationship building to communication between nurses and physicians.

\section{Limitations}

This study has some limitations worth noting. Our findings may not be generalizable beyond the four hospitals that participated, although we intentionally chose both academic teaching and community hospitals to derive a broader understanding of communication. The presence of researchers on each study unit may have caused participants to behave differently than they would have otherwise, although we took steps to minimize this effect such as the use of prolonged engagement ( 2 weeks at each site) and deriving findings from the analysis of multiple qualitative data sources. Rather than random selection, units within each hospital were chosen by hospital leadership possibly resulting in selection bias. Substantially less of the data presented here came from site 1 because hospitalists were geographically colocated on units with nurses that contributed to fewer communication difficulties being reported by nurses and physicians, which is in itself an interesting observation.

\section{CONCLUSIONS}

Patient care rounds are a crucial point in the care delivery process because during rounds, recent information is reviewed and new information that informs patient care is revealed through communication. Yet improving communication requires looking beyond the rounding process itself and bringing attention to three contextual dimensions of communication: organizational complexity, cognitive load, and the social context. Initiatives that seek to improve communication may be more successful if they acknowledge the complexity of communication and the context in which it occurs.

Acknowledgments: This project was supported by grant number R01HSO22305 from the Agency for Healthcare Research and Buality (AHRQ).

Corresponding Author: Milisa Manojlovich, PhD, RN, FAAN; School of Nursing, University of Michigan, Ann Arbor, MI, USA (e-mail: mmanojlo@umich.edu).

\section{Compliance with Ethical Standards:}

The university's institutional review board (IRB) approved the study and deemed the sites "not engaged" because none was involved in data collection. However, we also obtained site-specific IRB approval as requested by each site.

Conflict of Interest: Drs. Hofer and Manojlovich reports grants from AHRQ during the conduct of the study. Dr. Krein reports grants from the Agency for Healthcare Research and Quality, and grants from the Department of Veterans Affairs, Health Services Research \& Development Service, during the conduct of the study.

Disclaimer: The content is solely the responsibility of the authors and does not necessarily represent the official views of AHRQ.

\section{REFERENCES}

1. Leape LL, Shore MF, Dienstag JL, et al. Perspective: a culture of respect, part 1: the nature and causes of disrespectful behavior by physicians. Acad Med. 2012;87(7):845-852. https://doi.org/10.1097/ ACM.0b013e318258338d.

2. Sutcliffe KM, Lewton E, Rosenthal MM. Communication failures: an insidious contributor to medical mishaps. Acad Med. 2004;79(2):186194. http://www.ncbi.nlm.nih.gov/pubmed/14744724.

3. Gawande AA, Zinner MJ, Studdert DM, Brennan TA. Analysis of errors reported by surgeons at three teaching hospitals. Surgery. 2003;133(6):614-621. https://doi.org/10.1067/msy.2003.169.

4. Gruenberg DA, Shelton W, Rose SL, Rutter AE, Socaris S. Factors influencing length of stay in the intensive care unit. Am J Crit Care. 2006;15:502-509.

5. Wilson R, Runciman W, Gibberd R, Harrison B, Newby L, Hamilton J. The quality in Australian health care study. Med J Aust. 1995;163(6 November):458-471.

6. O'Leary KJ, Wayne DB, Landler MP, et al. Impact of localizing physicians to hospital units on nurse-physician communication and agreement on the plan of care. J Gen Intern Med. 2009;24(11):12231227. doi:https://doi.org/10.1007/s11606-009-1113-7

7. Zwarenstein $\mathbf{M}$, Rice $\mathbf{K}$, Gotlib-Conn $\mathbf{L}$, Kenaszchuk $\mathbf{C}$, Reeves $\mathbf{S}$. Disengaged: a qualitative study of communication and collaboration between physicians and other professions on general internal medicine wards. BMC Health Serv Res. 2013;13(1). https://doi.org/10.1186/ 1472-6963-13-494

8. Manojlovich M, Adler-Milstein J, Harrod M, et al. The effect of health information technology on health care provider communication: a mixedmethod protocol. JMIR Res Protoc. 2015;4(2). https://doi.org/10.2196/ resprot.4463 
9. Wu R, Lo V, Morra $\mathbf{D}$, et al. A smartphone-enabled communication system to improve hospital communication: usage and perceptions of medical trainees and nurses on general internal medicine wards. J Hosp Med. 2015;10(2):83-89. doi:https://doi.org/10.1002/jhm.2278

10. Solan LG, Beck AF, Shardo SA, et al. Caregiver perspectives on communication during hospitalization at an academic pediatric institution: a qualitative study. J Hosp Med. 2018;13(5):304-310. https://doi. org/10.12788/jhm.2919.

11. Chapman SA, Ritchie CS, Rehm RS, Wallhagen MI, Dudley N. Facilitators and barriers to interdisciplinary communication between providers in primary care and palliative care. $J$ Palliat Med. 2018;22(3):243-249. https://doi.org/10.1089/jpm.2018.0231.

12. Rice K, Zwarenstein M, Conn LG, Kenaszchuk C, Russell A, Reeves S. An intervention to improve interprofessional collaboration and communications: a comparative qualitative study. J Interprof Care. 2010;24(4):350-361. https://doi.org/10.3109/13561820903550713.

13. Walton V, Hogden A, Johnson J, Greenfield D. Ward rounds, participants, roles, and perceptions: literature review. Int $\mathrm{J}$ Health Care Qual Assur. 2016;29(4):364-379. https://doi.org/10.1108/IJHCQA-04-2015-0053.

14. Young JQ, ten Cate O, O'Sullivan PS, Irby DM. Unpacking the complexity of patient handoffs through the lens of cognitive load theory. Teach Learn Med. 2016;28(1):88-96. https://doi.org/10.1080/ 10401334.2015.1107491.

15. Thomas L, Donohue-Porter P, Stein Fishbein J. Impact of interruptions, distractions, and cognitive load on procedure failures and medication administration errors. J Nurs Care Qual. 2017;32(4):309-317. https://doi.org/10.1097/NCQ.0000000000000256.

16. Albolino S, Cook R, O'Connor M. Sensemaking, safety, and cooperative work in the intensive care unit. Cogn Technol Work. 2007;9(3):131-137. https://doi.org/10.1007/s10111-006-0057-5

17. Young E, Paulk J, Beck J, et al. Impact of altered medication administration time on interdisciplinary bedside rounds on academic medical ward. J Nurs Care Qual. 2017;32(3):218-225. https://doi.org/ 10.1097/NCQ.0000000000000233.

18. Holmgren AJ, Pfeifer E, Manojlovich M, Adler-Milstein J. A novel survey to examine the relationship between health IT adoption and nurse-physician communication. Appl Clin Inform. 2016;7(4):11821201. https://doi.org/10.4338/ACI-2016-08-RA-0145.

19. Manojlovich M, Harrod M, Holtz B, Hofer TP, Kuhn L, Krein SLSL. The use of multiple qualitative methods to characterize communication events between physicians and nurses. Health Commun. 2015;30(1):61-69. https://doi.org/10.1080/10410236.2013.835894.

20. Hsieh H-F, Shannon SE. Three approaches to qualitative content analysis. Qual Health Res. 2005;15(9):1277-1288. https://doi.org/10. $1177 / 1049732305276687$
21. Patton MQ. Qualitative Research \& Evaluation Methods. 3rd ed. Thousand Oaks: Sage Publications, Inc.; 2002.

22. Morse JM. Critical analysis of strategies for determining rigor in qualitative inquiry. Qual Health Res. 2015;25(9):1212-1222. https:// doi.org/10.1177/1049732315588501.

23. Pirnejad H, Niazkhani Z, Berg M, Bal RA. Intra-organizational communication in healthcare: considerations for standardization and ICT application. Methods Inf Med. 2008;47:336-345. https://doi.org/10.3414/ME0502.

24. Sandelowski M. Theory unmasked: the uses and guises of theory in qualitative research. Res Nurs Health. 1993;16(3):213-218. papers2:// publication/uuid/B975760B-FCE1-4AA8-BE6A-C6DC9BE4ACDB.

25. Zwarenstein $\mathbf{M}$, Goldman J, Reeves $\mathbf{S}$. Interprofessional collaboration: effects of practice-based interventions on professional practice and healthcare outcomes. Cochrane Database Syst Rev. 2009;(3):33. https://doi.org/10.1002/14651858.CD000072.pub2.

26. Urisman T, Garcia A, Harris HW. Impact of surgical intensive care unit interdisciplinary rounds on interprofessional collaboration and quality of care: mixed qualitative-quantitative study. Intensive Crit Care Nurs. 2018;44:18-23. doi:https://doi.org/10.1016/j.iccn.2017.07.001

27. Lewin S, Reeves S. Enacting "team" and "teamwork": using Goffman's theory of impression management to illuminate interprofessional practice on hospital wards. Soc Sci Med. 2011;72(10):1595-1602. https://doi. org/10.1016/j.socscimed.2011.03.037.

28. Huang KTL, Minahan J, Brita-Rossi P, et al. All together now: impact of a regionalization and bedside rounding initiative on the efficiency and inclusiveness of clinical rounds. J Hosp Med. 2017;12(03):150-156. https://doi.org/10.12788/jhm.2696

29. Gonzalo JD, Kuperman E, Lehman E, Haidet P. Bedside interprofessional rounds: perceptions of benefits and barriers by internal medicine nursing staff, attending physicians, and housestaff physicians. J Hosp Med. 2014;9(10):646-651. https://doi.org/10.1002/jhm.2245.

30. Alvarez G, Coiera E. Interruptive communication patterns in the intensive care unit ward round. Int J Med Inform. 2005;74(10):791796. https://doi.org/10.1016/j.ijmedinf.2005.03.017.

31. Wanzer MB, Wojtaszczyk AM, Kelly J. Nurses' perceptions of physicians' communication: the relationship among communication practices, satisfaction, and collaboration. Health Commun. 2009;24:683-691.

32. Manojlovich M, Kerr M, Davies B, Squires J, Mallick R, Rodger GL. Achieving a climate for patient safety by focusing on relationships. Int $J$ Qual Heal Care. 2014;26(6). https://doi.org/10.1093/intqhc/mzu068.

Publisher's Note Springer Nature remains neutral with regard to jurisdictional claims in published maps and institutional affiliations. 